\title{
Practical Difficulties and Countermeasures of Precise Poverty Alleviation Mechanism in Rural Areas
}

\author{
Maohe Zha \\ Party School of Taihu Committee of C.P.C, AnhuiTaihu, 246400
}

Keywords: rural areas; Targeted poverty alleviation; Predicament countermeasures

\begin{abstract}
The targeted poverty alleviation mechanism is implemented comprehensively to eliminate poverty and build a moderately prosperous society in all respects. Priority is given to the precision of poverty alleviation is China's development since the new century. In view of the poverty problem, a strategy is developed for poverty alleviation, social development and resource allocation of the new normal, poverty as the core, quality as well as the resources, to realize rural development to ensure effectiveness and comprehensive poverty alleviation policy, aiming at the problems existing in the poverty alleviation, and realizing the accurate and comprehensive, flexible and big efforts for developing the poverty alleviation work. In the implementation of the precise poverty alleviation mechanism in China's rural areas at the present stage, due to the existing problems such as accurate identification and precise assistance, the precise poverty alleviation mechanism has obvious practical difficulties, which requires further improvement and scientization. In view of the practical difficulties of the precise poverty alleviation mechanism in rural areas, this paper discusses how to realize the effective implementation of the precise poverty alleviation mechanism in development by combining the poverty alleviation work in rural areas of China.
\end{abstract}

\section{Introduction}

In the 19th conference, President xi jinping proposed that after the precision of poverty alleviation and development, the precision of poverty alleviation becomes the guiding goal of implementing and carrying out poverty alleviation policies in rural areas. Different from the traditional poverty alleviation work, the precision of poverty alleviation requires the accurate identification of the poor population, the precise implementation of poverty alleviation work, and the precision of poverty management and assessment, so as to realize the high efficiency, high quality and high level of poverty alleviation work, improve the effective use of resources and the scientific and comprehensive allocation of resources. Precision for poverty alleviation in rural areas mainly for rural development characteristics, geographic environment and poverty, with poverty alleviation and development about the innovation of the rural development and improvement of the guiding ideology, to ensure that the rural poor in anti-poverty policy, with the help of implementing multi-level poverty, avoid the traditional rural development concept's impact on poverty, achieve accurate full implementation of poverty alleviation mechanism.

\section{Practical difficulties in the targeted poverty alleviation mechanism in rural areas}

\section{1 lack of poverty alleviation identification mechanism, significant difference in standards}

At the present stage, the foundation of the establishment of the precise poverty alleviation mechanism in rural areas is insufficient, which makes it difficult to target the poor population in rural areas and implement the poverty alleviation policy in villages and homes. As a result, there is no way to accurately identify the poor population, which leads to problems in the implementation of the precise poverty alleviation policy. Serious differences on the one hand, rural poverty indicators, difficult to use the unified standards for identification for poverty alleviation, leads to poverty alleviation is difficult to accurately targeted to carry out, on the other hand, China's rural areas and there is no uniform standard and the working procedure, determine accurate poverty alleviation 
work to carry out the effective degree, makes it hard for poverty in many parts of the data check, prone to fraud problems, poverty alleviation work is the development of long-term work, eliminate poverty, first is to identify poverty to ensure that the poor precision of recognition to achieve accurate support, local governments are using one size fits all judgments, mainly on economic indicators to determine the poor, Although effective to identify the poor, but the judgment standard itself insufficient understanding of precision for poverty alleviation, precise poverty reduction is not only in view of the state of the economy, but also from the rural areas of culture, knowledge, education and so on poverty, shorten the gap between urban and rural development, ensuring the health of rural development, long-term and scientific, the accurate identification for poverty alleviation mechanism exists serious insufficient, lead to poverty alleviation work unable to effectively implement the [1].

\section{2 rigid poverty alleviation mechanism and insufficient support}

Even though the rural poor have moved away from the dilapidated residential areas, they still have no ability to change the nature of poverty. The local policy, carrying out the policy for poverty alleviation though positive, but not flexible application combined with local development, "ShuXieShi" poverty alleviation mode can not solve the poverty of rural environment, it is difficult to make thinking on poor people out of poverty and the environment, poverty, actively develop actively, the poverty alleviation work is not meaningful. Precision of poverty purpose is to let people living in poverty in rural areas themselves to stand up, get rich, with the help of the government and society to achieve high quality development, precision should be implemented for poverty alleviation and social docking, determination on the nature of the poor out of poverty, improve and market linkages to cooperate, ensure that in the process of poverty alleviation poverty researchers can actively change their state, stimulate their development flexibility, but it is a pity that precise degree of poverty alleviation system rigidity, flexible application combined with local development features, makes it hard for the poverty alleviation policy in the implementation of the combined with the demand and the poor rural development. A lot of poverty alleviation funds can't be used due to the provisions of the project content. For example, government support to build house, but most poor people are reluctant to build houses in the countryside, hoping children to live in the city in the future. However the poverty alleviation funds cannot be used to meet other needs of the poor, resulting in an obvious decline in the precision of poverty alleviation and difficulty in meeting the actual development needs of the poor ${ }^{[2]}$.

\section{Development countermeasures of targeted poverty alleviation mechanism in rural areas}

\subsection{Improve identification management and build a long-term support mechanism}

The realization of targeted poverty alleviation in rural areas needs to focus on accurate identification of dynamic management mechanism and go deep into countryside to improve the archives and personal data establishment of poor families, ensuring that the situation of the poor family can be timely reported to cadres to carry out such work as poverty alleviation. Therefore, the income index and multidimensional poverty index should be established as a standard of accurate identification of dynamic management mechanism. Using the Internet resources and the platform, establishment of poor families' archives should be improved by sifting the existing rural archives and investigating in the countryside, to increase the accurate identification of the poor. The government should update the poverty population in time, ensure to timely register the poverty and delete the family out of poverty, achieving high efficiency and standards of targeted poverty alleviation and effective implementation of poverty alleviation policy. Local governments should strengthen the sense of responsibility of counties, towns and townships using the established files and personal information. Apart from the implementation of the conventional support policies and work, it is necessary to make feasible poverty alleviation plans according to the poverty investigation, and to improve the effective utilization of poverty alleviation resources according to the differences and characteristics of different regions. The government should build a unified 
operation monitoring system and realize the cooperation of rural county using precise management system and the construction of large data of poverty alleviation. With the development advantages of local rural areas and the national strategy of "beautiful villages" and "innovation and entrepreneurship" in recent years, this paper discusses poverty alleviation programs from multi-angle, multi-diversity and multi-level to ensure the implementation of poverty alleviation funds and project supervision system ${ }^{[3]}$.

\subsection{Implement the central policy to stimulate the rural development}

Targeted poverty alleviation in rural areas is to realize poverty alleviation not only in economy but in development, realize the support of ability, knowledge and culture, and comprehensively improve the development level of the poor population in rural areas. From funds to training, from the subject consciousness to endogenous driving forces, the government should comprehensively and deeply carry out poverty alleviation and development, and put the central poverty alleviation policy in place. The poor families with strong will to overcome poverty should be supported first and set an example of poverty alleviation to stimulate the will of other poor families, making them move from negative poverty alleviation to overcoming poverty proactively, and improving the conditions and mentality of the poor families. The government should strengthen the main county-level responsibilities and provincial and municipal regulatory responsibility, ensure the ideological, cultural, economic leadership, introduce a series of preferential policy for poverty alleviation and strengthen the cooperation between all large banks to provide funds for poor families with creative entrepreneurial intention, to ensure that all the poor are helped and Party cadres take up their posts, realizing that rural poor area is full of village-resident teams and responsible individuals. In order to further adapt to the form of poverty alleviation, it is necessary to promote the standard management of the project, carry out the provincial alleviation goals in detail to all provinces, villages and households, and reform the funds management and supervision mechanism of special financial poverty alleviation from the origin of poverty. We should stimulate the initiative of poverty alleviation objects to overcome poverty positively, improve the financial poverty alleviation mechanism and the poverty information feedback mechanism using the information collected in villages, and raise the enthusiasm and sense of responsibility of cadres and poor households in poverty alleviation. The knowledge level and ability of the poor households can be improved through training of various skills and knowledge, cooperation with enterprises and institutions and connection with the local talent market. So that the deep poverty alleviation can be realized and farmers can obtain motivation of development through training and poverty alleviation to overcome poverty positively with the help of cadres ${ }^{[4-5]}$.

\section{Conclusion}

At present, China's targeted poverty alleviation work mainly includes relocation assistance, the promotion of whole deposit and industrial poverty alleviation and so on, which are only aimed at improving the living environment and economic income of the poor, failing to overcome poverty in thinking and ability. Only by realizing poverty reduction strategies that focus on rural development and meet ecological and environmental protection, implementing individualized and characteristic poverty alleviation programs, avoiding stereotyped and inefficient poverty alleviation, and implementing poverty alleviation through transparent operation mechanism, can we ensure the effective implementation of targeted poverty alleviation mechanism in rural areas.

\section{References}

[1] Zeng Lu. Practical difficulties and countermeasures analysis of targeted poverty alleviation in rural areas[J]. Knowledge Economy,2018(06):11-12.

[2] Wang Ping. Practical difficulties and countermeasures exploration of targeted poverty alleviation in rural areas[J]. China Business and Market,2018(06):53-54. 
[3] Chen Xiyong. Predicament and countermeasures of targeted poverty alleviation for industries in the mountain area -- investigation from Pingwu county, Sichuan province[J]. Rural Economy,2016(05):87-90.

[4] Fan Jianwei, Wang Yunlong. Practical difficulties and path selection of targeted poverty alleviation -- analyzing the survey of targeted poverty alleviation in Yunnan province[J]. Contemporary Economics,2017(02):7-9.

[5] Wang Zhili. Practical difficulties and breakthroughs of the targeted poverty alleviation strategy [J]. Leadership Science,2017(23):57-59. 